\title{
Drinking during marathon running in extreme heat: a video analysis study of the top finishers in the 2004 Athens Olympic marathons
}

\author{
Michelle van Rooyen (PhD) \\ Tamara Hew-Butler (PhD) \\ Timothy D Noakes (OMS, MB ChB, MD, DSc, FACSM, (Hons), FFSEM (UK) \\ UCT/MRC Research Unit for Exercise Science and Sports Medicine, Department of Human Biology, University of Cape Town
}

\begin{abstract}
Objective. To assess the drinking behaviours of top competitors during an Olympic marathon.

Methods. Retrospective video analysis of the top four finishers in both the male and female 2004 Athens Olympic marathons plus the pre-race favourite in the female race in order to assess total time spent drinking. One male and female runner involved in a laboratory drinking simulation trial.

Results. For the five female athletes, 37 of a possible 73 drinking episodes were captured. The female race winner was filmed at 11 of 15 drinking stations. Her total drinking time was 23.6 seconds; extrapolated over 15 seconds this would have increased to 32.2 seconds for a total of 27 sips of fluid during the race. Eighteen of a possible 60 drinking episodes for the top four male marathon finishers were filmed. The total drinking time for those 18 episodes was 11.4 seconds. A laboratory simulation found that a female athlete of approximately the same weight as the female Olympic winner might have been able to ingest a maximum of $810 \mathrm{ml}$ (350 $\mathrm{ml} . \mathrm{h}^{-1}$ ) from 27 sips whilst running at her best marathon pace whereas a male might have drunk a maximum of $720 \mathrm{ml}$ (330 $\mathrm{ml} . \mathrm{h}^{-1}$ ) from 9 sips under the same conditions.

Conclusions. These data suggest that both the female and male 2004 Olympic Marathon winners drank minimal total amounts of fluid $\left(<1\right.$ litre) in hot $\left(>30^{\circ} \mathrm{C}\right)$ temperatures while completing the marathon with race times within $2.5 \%$ of the Olympic record.
\end{abstract}

\section{CORRESPONDENCE:}

\section{Professor T D Noakes}

Department of Human Biology

Sports Science Institute of South Africa

Boundary Road

Newlands, 7925

Tel: +27 $21650-4557$

Fax: +27 $21686-7530$

E-mail: timothy.noakes@uct.ac.za

\section{Introduction}

Both the male and female marathons at the 2004 Athens Olympic Games were run in the hottest conditions experienced in any world-class marathon events in recent memory. At the start of the woman's race the temperature was $33^{\circ} \mathrm{C}$, and the relative humidity $(\mathrm{RH})$ was $31 \%$; conditions were only slightly more favourable for the men's events $\left(30^{\circ} \mathrm{C}\right.$; RH $\left.39 \%\right)$. By comparison, average early morning conditions during the 1996 Olympic Games in 'Hotlanta' were comparatively cool although the humidity was high (average daily temperature $22^{\circ} \mathrm{C}$; $\left.\mathrm{RH} 83 \%\right)^{1}$

When the race was run in 2004, the drinking guidelines then current $^{2-5}$ encouraged athletes to fully replace their body weight losses during exercise. If those guidelines were based on sound physiological principles, then it might be assumed that the athletes who performed the best in the 2004 Olympic Marathon races in Athens would have followed those guidelines. In other words, these individuals would have consumed at least 1 litre/h, amounting to a total of 2 - 2.5 litres during the race.

To establish whether the world's best runners adhered to the drinking guidelines current at that time, we retrospectively analysed the television broadcasts of the 2004 Athens Olympic marathons to determine the typical drinking behaviours of the top finishers in both races. As the television cameras followed the race leaders for the duration of the race, we were able to analyse only those athletes who were filmed at stations when they were running with the leading runners. To supplement these data, we also analysed the drinking behaviour of the pre-race favourite for the women's marathon. This individual, the world record holder, retired from the race at 36 $\mathrm{km}$. It appears that her inability to continue was likely due to the development of a limiting hyperthermia, but without progression to heatstroke. On the basis of prior, unsubstantiated observation, we postulated that these top-performing runners would drink less than advocated by the drinking guidelines.

\section{Materials and methods}

All data from the race television broadcast for leading runners passing through each of the 15 seconding stations (located every 2.5 $\mathrm{km}$ after $5.0 \mathrm{~km}$ in the male and female Athens 2004 Olympic marathons) were recorded and stored on a Sony PCG-GRV7P computer using the Dartfish 2.5.3.63 programme.

The four top finishers in both the male and female marathon were targeted. In addition, the drinking behaviour of the female world marathon record holder, who retired from the race at $36 \mathrm{~km}$, was also studied. 


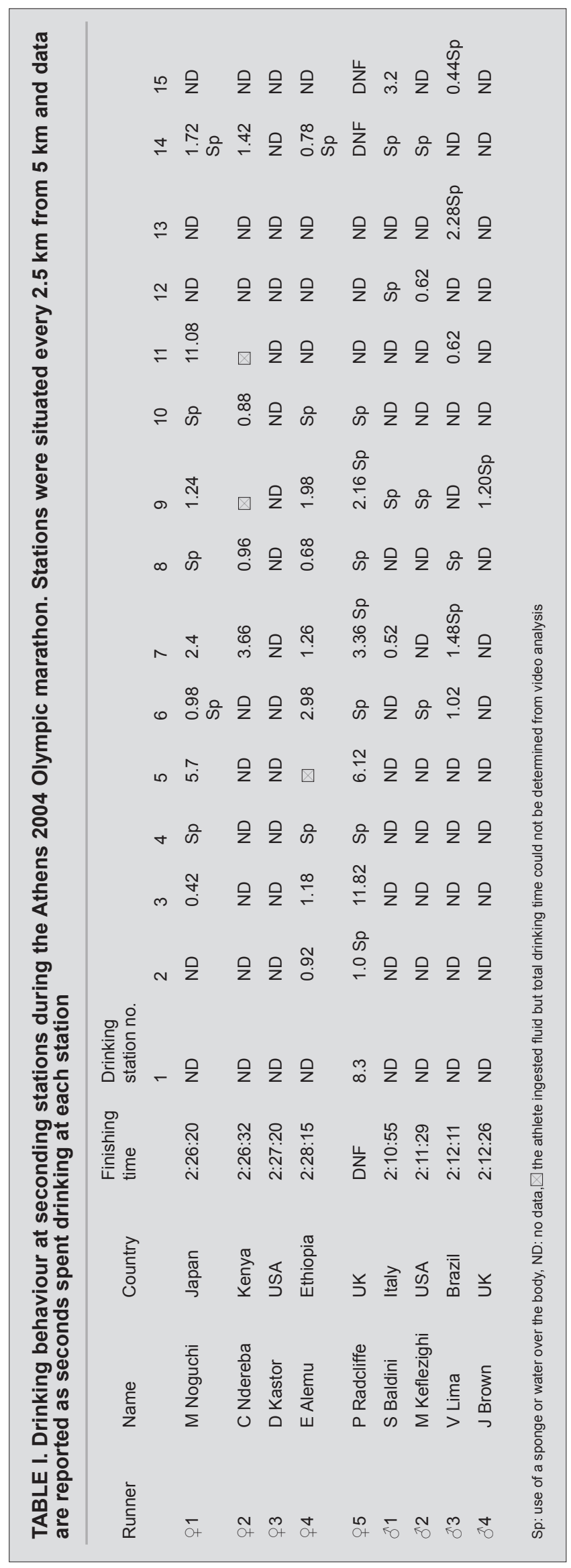

The video broadcast was analysed for the following

- Was the athlete's drinking behaviour at the seconding station recorded on the broadcast? If not, an entry of no data (ND) was recorded (Table I).

- If the athlete was visible on the tape, did he or she take a drinking bottle at the specific seconding station in review?

- If the athlete drank from the bottle, the number of times he or she drank from the bottle was recorded, as was

- The total time in seconds that each athlete drank from each bottle at each seconding station.

- Whether or not the athlete sponged him or herself at the seconding station was also recorded.

Data were collated and analysed to determine the total time each athlete was observed to be drinking whilst on camera. It was assumed that this behaviour was consistent across the entire race. Thus the behaviour of the athlete at the drinking stations that were captured on camera was extrapolated to those drinking stations at which he or she was not recorded. This allowed an estimate of the total time that each athlete spent drinking during the race.

As near complete data were available for one athlete - the 40 $\mathrm{kg}$ winner of the female marathon - we performed a laboratory simulation in which a female marathon runner of similar weight (43 $\mathrm{kg}$ ) reproduced the same drinking behaviour. This simulation was used to estimate the total volume of fluid that could be drunk in the same time that the female winner had been observed to be drinking during the Olympic marathon.

The female athlete ran at the equivalent of her best marathon pace whilst observing the edited video of the Olympic female marathon. On each occasion that the female race winner drank, the tested runner exactly reproduced the behaviour. It soon became apparent that the female race winner held the drinking bottle to her mouth for just long enough to fill her mouth. Therefore we performed an experiment to determine the maximum volume of fluid that our female subject could ingest, and which filled her mouth. This procedure was repeated with a male runner of $74 \mathrm{~kg}$.

In addition, in order to determine the limiting factors for drinking, we measured the peak flow rate that could be generated by applying maximum force with a single hand to two popular drink bottles, one large $(1000 \mathrm{ml})$ and one small $(500 \mathrm{ml})$, for $3-5$ seconds. We then calculated the volume of fluid ejected during this period and converted it to a flow rate in millilitres per second $(\mathrm{ml} / \mathrm{s})$.

\section{Results}

Despite the severe conditions in both Athens Olympic marathons, $66(80 \%)$ of the 82 female and $81(79 \%)$ of the 102 male entrants completed the race. To our knowledge, no runner developed heatstroke in either race although the female world record holder stopped running at $36 \mathrm{~km}$, perhaps as a result of severe hyperthermia that resolved spontaneously once she stopped running.

Table 1 shows the drinking behaviours of the 9 runners that were analysed. Data for the women's race were more complete as 37 of the possible $73(51 \%)$ drinking behaviours of the five studied runners were recorded on the television broadcast. Only $30 \%$ of the males' drinking behaviour was recorded. This reflected the different nature of the 2 races with 4 of the 5 women running in, or near, the lead group for the majority of the race. In contrast, 3 of the 4 top finishing males were close to the front for only the second half of the race. 


\section{TABLE II. Summary of drinking behaviour during the Athens 2004 Olympic marathon}

\begin{tabular}{|c|c|c|c|c|c|c|}
\hline \multirow[t]{2}{*}{ Runner } & \multicolumn{2}{|c|}{ Total drinking time on camera } & \multicolumn{2}{|c|}{ Extrapolated total drinking time } & \multicolumn{2}{|c|}{$\begin{array}{l}\text { Extrapolated total volume ingested during } \\
\text { the race }(\mathrm{ml})\end{array}$} \\
\hline & Seconds & No. sips & Seconds & No. sips & Max sip volume* & Peak flow rate volume ${ }^{* *}$ \\
\hline \multicolumn{7}{|l|}{ q } \\
\hline 1 & 23.60 & 20 & 32.0 & 27 & 810 & 1920 \\
\hline \multicolumn{7}{|l|}{ q } \\
\hline 2 & 6.92 & 6 & - & - & - & - \\
\hline \multicolumn{7}{|l|}{ q } \\
\hline 3 & ND & - & - & - & - & - \\
\hline \multicolumn{7}{|l|}{ q } \\
\hline 4 & 9.78 & 7 & 18.2 & 13 & 390 & 1080 \\
\hline \multicolumn{7}{|l|}{ q } \\
\hline 5 & 32.8 & 18 & 43.6 & 24 & 720 & 2640 \\
\hline \multicolumn{7}{|l|}{$\hat{\sigma}$} \\
\hline 1 & 3.72 & 3 & 11.2 & 9 & 720 & 660 \\
\hline \multicolumn{7}{|l|}{$\hat{\sigma}$} \\
\hline 2 & 0.62 & 1 & - & - & - & - \\
\hline \multicolumn{7}{|l|}{ 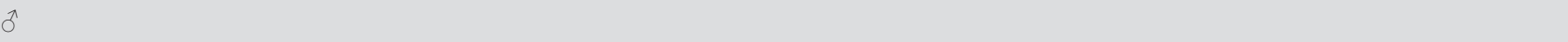 } \\
\hline 3 & 5.84 & 8 & 12.6 & 17 & 1360 & 780 \\
\hline \multicolumn{7}{|l|}{ 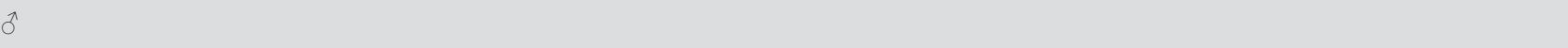 } \\
\hline 4 & 1.20 & 1.20 & - & - & - & - \\
\hline
\end{tabular}

Table II, which summarises drinking behaviour over the course of the race, shows that whilst she was on camera, the female race winner drank for a total of 23.6 seconds at the 11 drink stations at which she was filmed - a total of 20 sips of fluid. In addition, she sponged herself at 6 stations. If it is assumed that this behaviour pattern was consistent throughout the race, extrapolation to the 4 stations at which she was not filmed would suggest that she drank for a maximum duration of about 32 seconds during the race - a total of 27 sips of fluid.

Similarly, the female world record holder was filmed at 10 of the 13 aid stations that she would have passed during the race. She took 18 sips of fluid for a total of 32.8 seconds of drinking, and sponged herself at 6 of the stations. Thus her average drinking time at the 6 stations at which she drank was 5.4 seconds. Had she drunk in the same fashion at 2 of the 3 stations at which she was not filmed, her total drinking time during the race would have been 43.6 seconds $-a$ total of 24 sips.

The female athlete who finished in fourth place was also successfully filmed at 9 of the 15 aid stations. Her total drinking time was 9.78 seconds, and she took 7 sips of fluid. Extrapolated to all 15 aid stations, her total drinking time would have been 18.2 seconds (13 sips).

The less complete data for the male marathoners showed that the race winner drank at only 2 of the 5 stations at which he was filmed in the second half of the race (Table I). This would amount to a total of 3.72 seconds of drinking, comprising 3 sips of fluid (Table II). Extrapolating the same behaviour at $40 \%$ of the stations to the 15 drinking stations on the course, would have increased his total drinking time to 11.2 seconds from 9 sips of fluid. Similarly, the second finisher drank at only 1 of the 4 stations at which he was filmed for a total of 1 sip lasting 0.62 seconds. The third finisher drank at 6 of the 7 stations at which he was filmed for a total of 8 sips of fluid lasting 5.84 seconds. Extrapolating to the full race, he would likely have drunk at 13 of the 15 stations for a total duration of 12.6 seconds and 17 sips. Thus the drinking behaviours of these 5 athletes ranged from total drinking times of 18 - 44 seconds whilst ingesting between 13 and 27 sips of fluid.

Laboratory simulation found that the average volume of a 'sip' for a female runner of $43 \mathrm{~kg}$ was $30 \mathrm{ml}$, and that of a male runner of 74 $\mathrm{kg}$ was $80 \mathrm{ml}$. Thus the likely maximum amount of fluid ingested from 27 sips by the female race winner would have been approximately $810 \mathrm{ml}$, and that of the male race winner about $720 \mathrm{ml}$ from 9 sips (Table II). The greatest estimated fluid volume $(1360 \mathrm{ml})$ was that of the male runner who finished in third place.

The rate of flow from two different sports drink bottles was evaluated. The rate of flow from the $1000 \mathrm{ml}$ bottle was $100 \mathrm{ml} / \mathrm{s}$ while that from the $500 \mathrm{ml}$ bottle was $60 \mathrm{ml} / \mathrm{s}$. Only the smaller bottle would be used by marathon runners. A subsequent analysis using the same methods also found a similar flow rate of $50 \mathrm{ml} / \mathrm{s}$ from a similar drink bottle (Mr Lukas Beis, University of Glasgow: personal communication).

Accordingly, if the rate of fluid ingestion was limited by the peak flow rate of the drink bottles (probably $\sim 50-60 \mathrm{ml} / \mathrm{s}$ ) used by these athletes, and if the flow rate was always maximal when the bottle was in the athlete's mouth, which seems improbable, then the maximal fluid volumes that could have been ingested by these athletes ranged 
from $1080 \mathrm{ml}$ to $2640 \mathrm{ml}(430-1300 \mathrm{ml} / \mathrm{h})$ in the female runners, and from $660 \mathrm{ml}$ to $780 \mathrm{ml}(300-350 \mathrm{ml} / \mathrm{h})$ in the male runners.

The 1996 ACSM guidelines current in 2004 advise that athletes should drink $1.2 \mathrm{l} / \mathrm{h}$ (equivalent to $2620 \mathrm{ml}$ during a $2: 10: 55$ marathon by a male or to $2920 \mathrm{ml}$ during a 2:26:20 marathon by a female runner) to optimise performance. However, the true drinking behaviour of these world champions during international competition in extreme heat is estimated to be only $25 \%$ (male) to $31 \%$ (female) of these guidelines if drinking was limited by the size of the athlete's mouths, and between $25 \%$ (male) and $66 \%$ (female) if drinking was limited by the rate of fluid delivery from the drinking bottles.

What is more, if sweat rates were greater than $1.2 \mathrm{l} / \mathrm{h}$, as seems probable in these severe environmental conditions ${ }^{6,7}$ and if athletes are expected to drink sufficiently to 'replace all sweat losses during exercise', ${ }^{2}$ then the rates of fluid ingestion of these athletes would have been even more inadequate according to drinking guidelines then current. ${ }^{3-5}$

More recently (February 2007), the $\mathrm{ACSM}^{8}$ published revised guidelines which propose that athletes should drink 'to prevent excessive ( $>2 \%$ body weight loss from fluid deficit) dehydration and excessive changes in electrolyte balance from compromising performance and health' (p.386). Although the authors of the guidelines are reluctant to propose specific rates of fluid ingestion, they conclude that fluid ingestion rates of $400-800 \mathrm{ml}^{-\mathrm{h}^{-1}}$ are 'probably satisfactory for individuals participating in marathon length events'. Compared with these guidelines the male race winner probably drank at an estimated rate of $\sim 340 \mathrm{ml}^{-1}{ }^{-1}$ and the female at $\sim 350 \mathrm{ml}^{-1} \mathrm{~h}^{-1}$, rates which are below even the minimum range of these most recent ACSM guidelines. It is also of interest that the smaller female athlete may have drunk at a faster rate than her larger male peer.

\section{Discussion}

An important limitation of this study is that we did not record every drinking behaviour by all the top runners in both races in this event. The data from the men's race in particular, were less than ideal as only $30 \%$ of all possible drinking behaviours were filmed. We were not able to measure the actual volumes of fluid ingested by these athletes during the races; rather we made extrapolations based on the evidence from the race video and a crude measure of the average size of a 'sip' in athletes of the appropriate size. Nor did we measure the body weight changes in these athletes as a measure of dehydration. We did, however, accurately measure the maximum rate of fluid delivery from a typical sports drink bottle, similar to the type used in international marathon races. A subsequent study has confirmed this finding (Lukas Biel, University of Glasgow: unpublished findings).

The drinking behaviours of three of the leading female runners were far more complete with $29(67 \%)$ of the 43 possible drinking behaviours captured on the TV broadcast. This, at least, allows for broad conclusions regarding the drinking patterns of elite female marathon runners during the world's premier marathon race.

Our analysis suggests that in marathon races run in severe environmental conditions, the fastest female athletes spend between 18 and 45 seconds drinking - a total of $\sim 30$ sips of fluid during the race. This comprises about $0.5 \%$ of their total running time during the race. That they spent so little time drinking suggests that these elite female athletes do not place as much importance on fluid replacement during exercise as current drinking guidelines suggest they should. A more recent study of elite male marathon runners has confirmed that these athletes also drink for between 20 and 30 seconds during their marathon races (Lukas Beis, University of Glasgow: manuscript in preparation).

Our laboratory simulation suggests that the total volume of fluid ingested by the female and male winners of these races was about $800 \mathrm{ml}$ with an hourly rate of fluid ingestion of between 300 and $400 \mathrm{ml}^{-1} \mathrm{~h}^{-1}$. Although these rates of fluid ingestion were only $25-30 \%$ of the then current ACSM guidelines of $1.21 . \mathrm{h}^{-1}$, they are not different from rates recorded in runners competing before the 1970s. In that era, runners were actively discouraged from drinking as it was believed that drinking impaired athletic performance. ${ }^{9}$ The estimated rates $\left(\sim 340 \mathrm{ml}^{-1} \mathrm{~h}^{-1}\right.$ for the male winner; $\sim 350 \mathrm{ml.} \mathrm{h}^{-1}$ for the female winner) are also below the current range of $400-$ $800 \mathrm{ml.h} \mathrm{h}^{-1}$ considered 'probably satisfactory' in the revised (2007) ACSM guidelines. Interestingly, other studies ${ }^{10-13}$ have also found that elite runners drink at rates that are at the low end of the ACSM guidelines.

To check the likely accuracy of these predictions, we measured the peak flow rates from popular drink bottles designed for use during athletic competition. These showed that flow rates of $60 \mathrm{ml}^{-1}$ are probable. This would tend to confirm that subjects apply the bottles to their lips for sufficiently long $(\sim 1$ second) to fill their mouths with a single sip of between 30 and $80 \mathrm{ml}$.

On the other hand, if the drinking bottles provided fluid at the maximum rate $(\sim 60 \mathrm{ml} / \mathrm{s})$ for the entire duration that they were applied to each athlete's lips, then the absolute maximum volume of fluid that could have been drunk by the females rose substantially from $\sim 640$ $\mathrm{ml}$ to $\sim 1880 \mathrm{ml}$, with a maximum value of $2640 \mathrm{ml}$ (Table II). Yet even this maximum value for the female winner was still only $66 \%$ of the amount recommended at the time.

In contrast, this method of calculation caused the calculated amount of fluid ingested by the male runners to drop from $\sim 1040 \mathrm{ml}$ to $\sim 720 \mathrm{ml}$, or to less than $26 \%$ of the recommended volume.

Although the actual sweat rates of these athletes during these races were not reported, it is likely that their rates of fluid intake were substantially less than their sweat rates. For example, male and female runners running significantly more slowly in cooler conditions ( $25-32^{\circ} \mathrm{C}$; RH 62 - 82\%; wet bulb globe temperature index of 26.5 $-29.0^{\circ} \mathrm{C}$ ) in Atlanta, Georgia, were reported to sweat at mean rates of 1.7 and $1.3 \mathrm{I.h}^{-1}$ respectively. $^{7}$ These are among the highest sweat rates recorded in runners. It seems unlikely that the Olympic marathoners in these races who were running very much faster in more severe conditions would have sweated at lower rates. At sweat rates of between 1.3 and $1.7 \mathrm{l} . \mathrm{h}^{-1}$, but at fluid ingestion rates of only $300-800 \mathrm{ml}^{-1} \mathrm{~h}^{-1}$ (Table II), these athletes would have lost between 0.5 and $1.4 \mathrm{~kg} \cdot \mathrm{h}^{-1}$, and thus would have 'dehydrated' by at least 3 $4.5 \%$. These predictions match findings in other winning marathon runners. ${ }^{10-13}$

Thus, we conclude that athletes can win major competitive events run in extreme environmental conditions, even when consuming substantially less fluid than the recommended, developing an estimated $3-5 \%$ dehydration. This level of dehydration appears to pose no obvious risk to the individual's health, nor does it appear to impact performance. This is compatible with the theory that dehydration has a smaller impact on performance in trained athletes than is currently believed. ${ }^{14-15}$ Conversely, it is in contradiction to the theory that a $4 \%$ level of dehydration will cause a $30-50 \%$ reduction in exercise capacity (Fig. $4^{16}$ ) whereas a $5 \%$ weight loss will cause a reduction of between 45 and $65 \%$. Were these data correct, the 
female winner of the Athens Olympic marathon should have finished the race in between $3: 10: 14$ and 4:01:24, rather than in 2:26:20. It therefore appears that the data on which these predictions are based do not apply to the world's best athletes.

One of the reasons why world-class athletes may be quite unable to drink at the high rates proposed by these guidelines may simply be that such high rates produce discomfort in athletes running at high exercise intensities. Indeed, one of the core studies used by the ACSM to justify high rates of fluid ingestion during exercise concluded that runners were unable to sustain rates of fluid ingestion of $1.2 \mathrm{I}^{-\mathrm{h}^{-1}}$ for more than about $70-80$ minutes. $^{17}$ Thus the authors wrote: 'All of the runners experienced extreme sensations of fullness during the final five or six feedings. At the end of 100 minutes of running and feeding, it became apparent that further attempts to ingest fluids would have been intolerable' (p. 522). On the other hand, drinking ad libitum at lower rates $\left(\sim 250 \mathrm{ml}\right.$ every $5 \mathrm{~km} ; 500-700 \mathrm{ml}^{-\mathrm{h}^{-1}}$ for men and women respectively) during experimental $40 \mathrm{~km}$ running trials produced intestinal distress in only 2 of 12 subject. ${ }^{17}$ But when subjects combined walking, jogging and resting in the shade during a competitive $25 \mathrm{~km}$ military route march in $44^{\circ} \mathrm{C}$, they were able to drink up to $1.21 . \mathrm{h}^{-1}$ without developing symptoms of intestinal discomfort (Nolte $\mathrm{H}$ et al.: manuscript submitted). This suggests that it is the act of running which causes intestinal symptoms when the rates of fluid ingestion are high.

Alternatively, these guidelines may have encouraged a drinking behaviour that elite athletes are unable to follow simply because humans evolved specifically to be able to run in the heat without requiring concurrent fluid replacement. Thus one theory ${ }^{18}$ holds that the ability to sweat and, as a consequence, to become dehydrated, provided humans with a critical evolutionary advantage since it allowed humans to add high-quality protein to their diets. Thus their ability to sweat, and therefore to remain in thermal balance during prolonged exercise in the heat, allowed ancestral humans hunting on the African plains to chase large, non-sweating antelope until their exhaustion presumably as a result of hyperthermia. ${ }^{19}$ Sweating allowed humans better to regulate their body temperatures during such exercise in extreme dry heat (up to $46^{\circ} \mathrm{C}^{20}$ ), thereby avoiding the hyperthermia that caused their prey to become paralysed, and hence dispatchable at close quarters.

The remarkable performances of the tiny, light-boned, elite marathon runners of today, like the $40 \mathrm{~kg}$ winner of the 2004 Athens Olympic women's marathon, Mizuki Noguchi, in extreme heat suggest the continued presence of these remarkable evolutionary adaptations. ${ }^{21}$ High sweating rates, that are not reduced by a developing dehydration, ${ }^{17,22,23}$ and the ability to run in extreme heat for up to 6 hours without significant fluid ingestion ${ }^{20}$ seem to confirm that humans are remarkably well adapted for running in dry heat, as again confirmed by the exceptional performances of real athletes in actual Olympic competitions.

Elsewhere $^{24}$ we have also shown that elite Kenyan distance runners drinking ad libitum at rest and during training ingest fluid at rates that appear to be low compared with modern drinking guidelines.

\section{REFERENCES}

1. Sparling PB. Environmental conditions during the 1996 Olympic Games: a brief follow-up report. Clin J Sport Med. 1997;7(3):159-161.

2. Armstrong LE, Epstein Y, Greenleaf JE, et al. American College of Sports Medicine position stand. Heat and cold illnesses during distance running. Med Sci Sports Exer 1996;28(12):i-X.

3. Casa DJ, Armstrong LE, Hillman SK. National Athletic Trainers Association Position Statement: Fluid replacement for athletes. J Athl Train 2000;35:212-224

4. Convertino VA, Armstrong LE, Coyle EF, et al. American College of Sports Medicine position stand. Exercise and fluid replacement. Med Sci Sports Exer 1996;28(1):i-vii.

5. American College of Sports Medicine, American Dietetic Association, Dietitians of Canada. Joint Position Statement: nutrition and athletic performance. Med Sci Sports Exerc 2000;32(12):2130-2145.

6. Fowkes Godek S, Bartolozzi AR, Godek JJ. Sweat rate and fluid turnove in American football players compared with runners in a hot and humid environment. Br J Sports Med 2005;39(4):205-211.

7. Millard-Stafford M, Sparling PB, Rosskopf LB, Snow TK, DiCarlo LJ, Hinson BT. Fluid intake in male and female runners during a $40-\mathrm{km}$ field run in the heat. Journal of Sports Sciences. 1995;13(3):257-263.

8. Sawka MN, Burke LM, Eichner ER, Maughan RJ, Montain SJ, Stachenfeld NS. American College of Sports Medicine position stand. Exercise and fluid replacement. Med Sci Sports Exerc 2007;39(2):377-390.

9. Noakes TD. Lore of Running. 4th ed. Champaign, IL: Human Kinetics Publishers, 2003

10. Wyndham $\mathrm{CH}$, Strydom NB. The danger of an inadequate water intake during marathon running. S Afr Med J 1969;43(29):893-896.

11. Pugh LG, Corbett JL, Johnson RH. Rectal temperatures, weight losses, and sweat rates in marathon running. J Appl Physiol 1967;23(3):347352.

12. Muir AL, Percy-Robb IW, Davidson IA, Walsh EG, Passmore R. Physiological aspects of the Edinburgh Commonwealth Games. Lancet 1970;2(7683):1125-1128.

13. Buskirk ER, Beetham WPJ. Dehydration and body temperature as a result of marathon running. Medicina Sportiva 1960;XIV(9):493-506.

14. Sharwood KA, Collins M, Goedecke JH, Wilson G, Noakes TD. Weight changes, medical complications, and performance during an Ironman triathlon. Br J Sports Med 2004;38(6):718-724.

15. Noakes TD. Dehydration during exercise: what are the real dangers? Clinical Journal of Sport Medicine 1995;5(2):123-128.

16. Sawka MN, Montain SJ. Fluid and electrolyte supplementation for exercise heat stress. Am J Clin Nutr 2000;72(2 Suppl):564S-572S.

17. Costill DL, Kammer WF, Fisher A. Fluid ingestion during distance running Arch Environ Health 1970;21(4):520-525.

18. Heinrich B. Racing the antelope. First. New York: Harper Collins Publishers Inc., 2001.

19. Gonzalez-Alonso J, Teller C, Andersen SL, Jensen FB, Hyldig T, Nielsen $B$. Influence of body temperature on the development of fatigue during prolonged exercise in the heat. J Appl Physiol 1999;86(3):1032-1039.

20. Foster C, Foster D. Speaking with earth and sky. Cape Town: David Phillips Publishers, 2005

21. Bramble DM, Lieberman DE. Endurance running and the evolution of Homo. Nature 2004;432(7015):345-352.

22. Eichna LW, Bean WB, Ashe WF, Nelson N. Performance in relation to environmental temperature. Bull Johns Hopkins Hospital 1945;76:25-58.

23. Montain SJ, Coyle EF. Influence of graded dehydration on hyperthermia and cardiovascular drift during exercise. J Appl Physiol 1992;73(4):13401350

24. Fudge BW, Easton C, Kingsmore D, et al. Elite Kenyan endurance runners are hydrated day-to-day with ad libitum fluid intake. Med Sci Sports Exerc 2008;40(6):1171-1179. 